\title{
Desde las montañas del sureste
}

Kristine VANDEN BERGHE

Universidad de Lieja/FundP-Namur, Bélgica

En diciembre de 1995, se registró formalmente la candidatura del Subcomandante Marcos para el Premio Chiapas en Arte como «escritor del pueblo». Gran entusiasta del Ejército Zapatista de Liberación Nacional, Régis Debray afirmó el mismo año que Marcos era el mejor escritor latinoamericano del momento (1995) mientras Hermann Bellinghausen lo proclamó el escritor de izquierda más leído y apreciado en México (en Vázquez Montalbán 1999: 210). El que la prosa de Marcos no sólo fuera apreciada por sus correligionarios, lo demostraba la valorización de Octavio Paz quien, desde una posición ideológica distinta, se refirió a la renovación que significaba para el lenguaje político (1994: 57). Marcos, conocido sobre todo como portavoz del EZLN, ganó por lo tanto también fama como escritor. En esta contribución se estudiarán algunos aspectos significativos de sus relatos de ficción a partir de un análisis de los protagonistas de éstos, respectivamente el Viejo Antonio, don Durito de la Lacandona, Elías y varios personajes trasuntos del autor. Pero antes de entrar en esta materia cabe presentar brevemente los rasgos básicos de los textos.

\section{Armas y letras}

Los comunicados zapatistas suelen ser introducidos por o concebidos como cartas que, a menudo, llevan posdatas. La inclusión de una posdata en una correspondencia guerrillera llama la atención porque el género de la posdata no suele asociarse con un género público como el panfleto político o el comunicado de una guerrilla y más bien hace pensar en la correspondencia informal. Muchas cartas zapatistas incluso llevan más de una posdata, lo cual es aún más sorprendente, pues hace que los textos de la guerrilla se vayan construyendo mediante excrecencias y prolongaciones que tienen un efecto de multiplica- 
ción y dispersión. En una ocasión, una carta (comunicado del 11 de marzo de 1995 en EZLN 1995: 256) lleva hasta ocho posdatas que se construyen como cajas chinas, una posdata sirviendo de marco a un comentario en el cual se intercala un soneto seguido a su vez por otra posdata, etc. Las convenciones genéricas se subvierten de manera constante, también mediante la inversión de la jerarquía tradicional entre carta y posdata, porque en numerosos casos las posdatas son más largas que las cartas y éstas se convierten en meras introducciones a aquéllas. Aparte de que las posdatas emplean imágenes literarias y juegan con los sentidos y los sonidos de las palabras, algunas integran relatos. De esta manera constituyen una especie de añadidura literaria a comunicados que informan sobre la coyuntura en la zona del conflicto, las demandas del EZLN o la política mexicana. Mientras que muchos otros textos del EzLN son firmados por la Comandancia General Indígena, el autor de los textos de ficción es el Subcomandante Marcos.

Los relatos pueden dividirse en dos series según el protagonista que aparezca en ellos. El primero es un anciano indígena maya, el Viejo Antonio. Apareció por primera vez en un texto de agosto de 1992, dirigido a los indígenas de la región, texto que se hizo público a una escala más amplia el 28 de mayo de 1994. Los relatos del Viejo Antonio son breves textos cosmogónicos, fábulas y alegorías que parecen inspiradas en las tradiciones autóctonas, en los que los siete dioses primeros establecen el orden según el cual los hombres han de vivir. Antonio los cuenta a otro personaje, el "yo", que es el primer trasunto del autor Marcos. La segunda figura protagónica es Durito, un escarabajo que se presenta bajo diversas identidades, la más frecuente siendo la del caballero andante don Durito de la Lacandona. El escarabajo apareció por primera vez en un comunicado (10 de abril de 1994) que Marcos escribió para una niña en agradecimiento por un dibujo que ésta le había enviado, y volvió a hacer su aparición a partir de 1995. Los relatos sobre Durito más bien son reflexiones y juegos de escritura en apariencia espontáneos y a veces algo desordenados. Su estilo tanto como sus temas se diferencian de los relatos del Viejo Antonio. Mientras que éstos amplían el canon literario mexicano con mitos indígenas, las historias sobre Durito se construyen esencialmente con aportes de la cultura occidental contemporánea y son representativas de la era del pastiche. Pero por más distintas que sean, ambas series están al servicio del proyecto político de los zapatistas. Esto no quiere decir que representen las ideas del EZLN o sus verdaderos objetivos, sino que, en virtud de su naturaleza pública, reflejan los esfuerzos de Marcos por dar forma a la imagen de los zapatistas e influir a la sociedad en su favor. El propio Subcomandante (Le Bot 1997: 356) ha corroborado esto al decir que considera los cuentos como un arma dirigida al corazón de sus lectores.

Otra coincidencia entre los relatos de Antonio y los textos sobre Durito es que han acabado por tener una vida independiente de los comunicados, pues han sido reunidos en distintas antologías. El lector tuvo acceso, respectivamente en 1998 y en 1999, a dos libros que recogen una gran cantidad de los relatos, Relatos de el Viejo Antonio (VA) y Don Durito de la Lacandona (DD). Cuando se publicaron bajo forma de antologías, la naturaleza de los relatos cambió. Perdieron su posición híbrida y liminal de posdata a la par de que se incrementó la comodidad de la lectura y el respeto por las normas literarias tradicionales. Paralelamente desapareció la información contextual. Cuando aparecían bajo forma de posdatas, los relatos de Marcos expresaban más de una vez de manera metafórica algunos aspectos de los comunicados a los que acompañaban, ${ }^{1}$ intercalando de esta manera un nivel literario intermedio de referencia. En el caso de la publicación bajo forma de libros, la desaparición de los comunicados propiamente políticos que acompañaban originalmente las posdatas, implica una disminución de las referencias al contexto. Reunidos en las antologías, los relatos ya no funcionan tanto como pantallas de percepción de una realidad militar y política, sino que permiten que el lector escape a zonas de ensueño alejadas de esa realidad. La catalogización de los libros del EZLN en las librerías del DF comprueba la «literaturización" que se ha ido operando sobre una parte de los textos zapatistas. Mientras que los primeros volúmenes de comunicados están colocados en la sección "política», algunos de los posteriores se encuentran bajo el rótulo de «literatura".

La normalización y la literaturización del discurso zapatista llevan consigo que se incrementa el protagonismo del Subcomandante en calidad de autor. Los volúmenes que reúnen los comunicados zapatistas publicados en la prensa han sido publicados por la editorial Era bajo la autoría del EZLN. En cambio, los libros que publican los relatos de manera separada y varias antologías posteriores, aun cuando incluyen textos redactados por la Comandancia General del EzLN, llevan a Marcos como autor. ${ }^{2}$

1 En el libro que reúne los textos sobre Durito, la reminiscencia de su publicación inicial en la prensa es mayor porque, contrariamente a lo que pasa con los relatos del Viejo Antonio, al final de los rexcos sobre Durito se menciona la fecha original de su publicación.

2 Aparece como autor de los dos libros mencionados y de orros volúmenes que recogen los mismos relatos u otros comunicados zapatistas, La historia de los colores (1996), Cuentos para una 
La normalización del discurso, su literaturización y la creciente visibilidad del Subcomandante se confirmaron en 2005 con la publicación de Muertos incómodos, una novela policíaca de la que Marcos escribió los capírulos impares y Paco Ignacio Taibo II los pares. La escritura a cuatro manos, el hecho de que la novela haya aparecido originalmente como folletín ${ }^{3}$ y que se pueda bajar gratis de Internet constituyen algunos de sus rasgos más sorprendentes. La historia principal narrada por Marcos comienza con el descubrimiento de un fajo de papeles, lo cual sitúa la novela en la tradición del manuscrito hallado. Manuel Vázquez Montalbán, simpatizante de los zapatistas y cuya muerre en 2003 impidió que fuera el tercer autor de la novela, dejó un expediente sobre las actividades sospechosas de un tal Morales que su hijo envía al Subcomandante por mediación de Pepe Carvalho. Marcos decide encargar al zaparista Elías Contreras la investigación del asunto. Para realizar su objetivo, Contreras debe viajar al Distrito Federal antes de volver a Chiapas donde captura a Morales. Resulta que éste desempeńó el papel de intermediario al servicio de una red de personas poderosas que querían privatizar la región de Aguas Azules para enriquecerse con los recursos naturales en la zona. Se le condena a diez años de trabajo comunitario.

Esta historia alterna con otra en los capítulos pares, escritos por Taibo II. Héctor Monteverde recibe llamadas de cierto Alvarado, un viejo amigo suyo. Las llamadas son extrañas, pues Alvarado fue asesinado por un tal Morales tras salir de la cárcel en 1971. Monteverde acude al detective privado Héctor Belascoarán Shayne, conocido por los lectores de las novelas de Taibo II, quien se ocupará del caso. El detective encuentra a Morales en una oficina de la Torre Latinoamericana y al darse cuenta de que es "un canalla menor", se limita a darle un empujón de modo que rueda por las escaleras 41 pisos hasta la calle. Las dos tramas se entrelazan porque Marcos envía a Elías al Distrito Federal para consultar sobre «su» caso Morales con Belascoarán, un viejo conocido suyo. También coinciden porque los dos criminales se apellidan Morales, lo cual sugiere que el mal es impersonal.

El libro Noches de fuego y desvelo (2007) ha sido, hasta ahora, la más reciente incursión de Marcos en el terreno literario y más específicamente en el de la

soledad desvelada (1997), Siete piezas sueltas del rompecabezas mundial (1999), Desde las montañas del sureste mexicano (Cuentos, leyendas y otras posdatas del Sup Marcos) (2000) y Detrás de nosotros estamos ustedes (2000)

${ }^{3}$ En La Jornada. poesía erótica. Mientras que Muertos incómodos se puede bajar gratis de internet, este último libro tiene una tirada limitada de 1000 ejemplares, no se vende en las librerías y cuesta unos 61 euros, los cuales se destinan a proyectos de salud en comunidades indígenas de Chiapas. Por ser de acceso tan dificil, no ha padido ser tomado en consideración en el presente ensayo.

\section{El Viejo Antonio}

En el prólogo de los Relatos de el Viejo Antonio, Armando Bartra aprecia que Marcos presente al personaje como un individuo, lo cual le habría permitido escapar al racismo inherente a las representaciones colectivas de los indígenas:

Antonio no es un personaje propio de la cultura occidental colado en el 'impersonal' mundo indígena. Sin duda las comunidades rurales tienen en la preeminencia de lo colectivo su condición de sobrevivencia dencro de un mundo hostil, pero esto no implica ausencia de individuación. La hipótesis de que las singularidades humanas son atriburo "civilizado", mientras que lo propio de las sociedades agrarias es el comunitarismo indiferenciado, se parece mucho a la noción popular de que todos los "negros", o los "chinos", o los "indios" son iguales. (1998: 16)

Sometamos a prueba la tesis de Bartra y analicemos cómo Marcos construye el personaje de Antonio.

Su edad avanzada es el rasgo básico del personaje que se deduce de su propio nombre. No sólo transmite una idea de sabiduría y de autoridad moral, sino que además ésta va asociada al cansancio y a la enfermedad. Al principio del libro, Marcos presenta a la familia de Antonio. El anciano se despierta y «ve a su mujer en cuclillas atizar el fogón, oye a su hijo llorar, mira el sol saludando al oriente, y afila su machete mientras sonríem (VA 19). Esta escena de tipo costumbrista representa a los miembros de la familia en ocupaciones tradicionales e ilustra la felicidad rústica del Viejo Antonio y su cercanía a la naturaleza. También tenía una hija, pero se le murió de hambre : «El Viejo Antonio acababa de enterrar a uno de sus hijos. "No se logró", dijo el Viejo Antonio después de poner la cruz, amarrada con bejuco, que marcaba la tumba de una niña, de la niña que Dońa Juanita y él, el Viejo Antonio, habían hecho para que viviera" (VA 94). El propio Viejo Antonio murió a su vez de la tuberculosis. El Viejo Antonio aparece aquí como un personaje material y fisicamente miserable, pero espiritualmente rico que vive en comunión con el universo. Son rasgos que 
reproducen los estereotipos básicos de los indígenas difundidos por uno de los imaginarios más tradicionales que existen en torno a ellos y que son prototípicos de la novela indigenista. El hecho de que Marcos lo aísle de los demás indígenas basándose en su sabiduria es otro rasgo destacado por Henri Favre como típico de esta novela (1998: 69). Esto lleva a refutar a Armando Bartra y a postular que el Viejo Antonio, no obstante algunas características individualizadoras, es básicamente un personaje estereoripado. Sus retratos -así como la falta de espesor psicológico- disminuyen su individualidad hasta tal grado que es fácil verlo como una encarnación del pueblo indígena.

Si Antonio enlaza los dos planos de la narración - el marco y los relatos intercalados - mediante su voz al contar los mitos al "yo", también los enlaza porque se lo puede ver como el representante más o menos individualizado pero estereotipado del actante colectivo - - los hombres verdaderos- que protagonizan los relatos que cuenta. Esta asociación entre el individuo y la comunidad se deduce de la frase siguiente dicha por el "yo»: «Con él, con el Viejo Antonio, se sientan junto conmigo todos los hombres y mujeres de morena sangre en corazón digno" (VA 102). La frase reúne los dos aspectos a partir de los cuales Marcos caracteriza a las comunidades indígenas. La expresión "morena sangre" indica un principio de identidad biológico-racial, lo que permite decir que la presentación de los indígenas en los relatos se hace a partir del color moreno de la sangre que señala metonímicamente la oscuridad de la piel. Esas referencias cromáticas se asocian con una identidad moral señalada en la expresión "corazón digno".

La asociación es particularmente evidente en el relato sobre la génesis del sol y de la luna. Los dioses están discutiendo sobre cómo se podría hacer más luz y disminuir la frecuencia de la noche. Piensan que se podría sacrificar el dios más blanco porque daría la luz más hermosa, pero como éste rehúsa, ofrece sacrificarse el dios más negro:

$Y$ una rueda hicieron los dioses en torno al fuego y echaron en discutir quién debía llevar el fuego para arriba y morirse abajo para vivir arriba, y no se ponían de acuerdo los dioses porque no se querían morir abajo los dioses, y dijeron los dioses que vaya el dios más blanco, porque era el más hermoso y así el fuego sería hermoso allá arriba, pero el dios blanco fue cobarde y no quería morirse para vivir, y entonces el más negro y más feo de los dioses, el ik', dijo que él lo llevaba para arriba al fuego y se dio en agarrarlo el fuego y se quemó con el fuego y negro se puso y gris después y blanco y amarillo y naranja después y rojo luego y fuego se hizo. (VA 35-36)
Los colores oscuros se asocian con la moral de sacrificio de un individuo o un grupo para el bienestar de todos. De esta manera, en el retrato que Marcos hace de los indígenas domina el prometeismo. Ya que establecen una relación determinista entre el indigena y una moral digna, los Relatos de el Viejo Antonio incluyen categorías que desde hace mucho tiempo han adquirido la transparencia del estereotipo del buen indio frente a su explotador. Acaban por componer un retrato nativista de los indígenas, no porque impliquen una actitud romántica que mira hacia el pasado con nostalgia - hay poco de esto en los relatos de Marcos-, sino porque idealizan a los indigenas. En este sentido, se ubican dentro de las tendencias indianistas actuales (Favre 1998: 132).

El etnocentrismo se desprende también de la reescritura que Marcos ha hecho del Popol Vuh. En la versión del Viejo Antonio, los dioses crearon primero la gente de oro. Pero ésta no se movía y decidieron engendrar al hombre de madera. Mas como éste fue explotado por su compañero de oro que le mandaba trabajar, los dioses crearon al hombre de maíz, "los hombres y mujeres verdaderos" que "hablaron la lengua verdadera" (VA 22). Una lectura rápida podría recalcar las coincidencias entre el relato del Viejo Antonio y el mito del Popol Vuh: ambos representan la creación de la especie en ambos el hombre verdadero, está hecho de maíz.

Sin embargo, también interesan las desviaciones frente al Popol Vuh. La humana como un proceso que precisa de varias tentativas antes de llegar a buen término y lógica de sustitución de varios tipos de hombres en el Popol Vuh se transforma en una lógica de simultaneidad en el relato de Marcos: el hombre de madera no sustituye al de oro, sino que viene a hacerle compañia. Esta reescritura permite presentar a los dos en una relación conflictiva. La segunda variante debe leerse a partir de esta relación. En el Popol Vuh, el hombre anterior al de madera fue de barro. Al sustituirlo por una figura de oro, Marcos sustituye la sucesión de dos materiales pobres por una oposición entre un material precioso y de color claro que remite a los no indígenas ricos, y una materia más común y oscura, que se refiere a los indígenas pobres. A partir de un mito maya conocido y por la voz del Viejo Antonio, Marcos teje una alegoría sobre la explotación de los indígenas por los mestizos y los blancos. El antagonismo es en primer lugar una oposición social, los pobres son explotados por los ricos. No obstante, la realidad social es definida más en términos étnicos que a partir de relaciones de clase.

Si los retratos del hombre de oro y de madera son nativistas por la oposición entre ambos y por sus respectivas descripciones, el retrato del hombre de maíz 
corresponde a una visión menos etnocéntrica porque supera las divergencias. Marcos lo describe como una figura utópica que simboliza al que no explota a los demás ni se deja mandar. El giro que toma aquí el simbolismo cromático es significativo de una postura alter/nativista. El hombre de maíz, el verdadero o igualitario, es indefinido en cuanto al color pero se asocia con los zapatistas, los sin rostro:

Le pregunté al Viejo Antonio de qué color era la piel de las gentes de maíz y me enseńó varios tipos de maiz, de colores diversos, y me dijo que eran de todas las pieles pero nadie sabía bien porque las gentes de maíz, los hombres y mujeres verdaderos, no tenían rostro. (VA. 22)

Antonio concluye otra narración diciendo: «el mundo será alegre si todos los colores y todos los pensamientos tienen su lugar" (VA 49). Estas afirmaciones contradicen otro relato en el que el hombre de maiz, el verdadero, es definido como indígena, del "color de la tierra" (VA 43). La contradicción es ejemplo de las tensiones constantes en los relatos entre una postura nativista y una postura reacia a entablar una relación determinista entre etnia y moral.

En los relatos del Viejo Antonio, Marcos también ha intentado apropiarse del español de manera que su uso dé cuenta de la realidad local y de las demandas indígenas. Un análisis centrado en la lengua revela una preocupación por desarticular e hibridizar el español mexicano mediante fusiones de la sintaxis del español con sintaxis desviantes. Esta práctica, bastante frecuente en la novelística hispanoamericana y chiapaneca de tipo indigenista (Lienhard 2003: 283), resulta en un genuino interlenguaje (Ashcroft e. a. 1989: 66) que enfatiza la diferencia entre el espańol y las lenguas indígenas y que pide al lector hispanohablante que se comprometa activamente con la otra cultura. Entre las distorsiones más sistemáticas está el uso transitivo de verbos normalmente intransitivos. Destaca el empleo del verbo nacer con un complemento objeto directo, una combinación que resulta en frases como «los dioses nacieron el mundon (VA 82, 87). El uso transitivo de verbos intransitivos no se limita a los fragmentos donde habla el indígena, sino que se registra también en el lenguaje del narrador que escribe: "La mar dormitaba el cansancio que el amor regala", «el avión había ya ronroneado la muerte» (VA 108) y "los hombres y mujeres verdaderos nacen de nuevo la palabra" (VA 112). Otra desviación lingüística frecuente es la combinación insólita de verbos que suelen tener un complemento objeto directo tangible con un complemento que no lo es: «El Viejo
Antonio pone la palabra en el suelo» (VA 63), "mordisquea la palabra» (VA 70) $\mathrm{y}$ "corta bejucos y húmedos pedazos de noche» (VA 105). En los relatos abunda asimismo la repetición del mismo concepto, una modalidad estilística propia de las literaturas mesoamericanas (de la Garza 1980: XXXVII) que aumenta el carácter poético de los textos. Es el caso de frases como: "grande fue el dolor que, hecho lágrimas, alivió el dolor que doliendo se dolía en la tierra» (VA 54) o «sólo si lo caminaban el camino largo iban a saber a dónde lleva porque así como estaban nunca iban a saber para dónde lleva el camino largo" (VA 59), "los dioses primeros, los que formaron el mundo» (78), «los dioses primeros, los que nacieron el mundo», «el seńor de la oscuridad, el desparejador del mundo" (VA 79), etc.

Es probable que Marcos haya querido despertar ecos al ritmo de las lenguas mayas e integrar una gama de alusiones a ellas. También es claro que quiere dar cuenta de la realidad en el plano local y que las desarticulaciones reflejan las lenguas híbridas en las que muchos chiapanecos han llegado a expresarse por sus desplazamientos debidos a razones políticas y económicas (De Vos 2002). De esta manera, la lengua discordante recuerda las difíciles negociaciones que constituyen la historia local. Simultáneamente, la hibridación de la lengua refleja las reivindicaciones de los zapatistas en el plano nacional. Mediante ella, se rechaza el carácter oficialmente monoglósico de México y se subvierten los presupuestos culturales, políticos y epistémicos transmitidos por ese monolingüismo. Las variaciones lingüísticas funcionan entonces como una metonimia de las diferencias culturales de los pueblos indígenas frente a sus conciudadanos mestizos. Asimismo, las tensiones en el texto entre la norma española y las desviaciones frente a ella traducen una tensión del contexto, la lucha de los indígenas mediante las negociaciones de San Andrés por ver sus diferencias reconocidas dentro de un estado plurilingüe e intercultural.

\section{Don Durito de la Lacandona}

Después del Viejo Antonio, Marcos creó el personaje de Durito, un escarabajo de caparazón duro. Los textos sobre Durito a menudo son breves, sin trama clara y suelen dar cuenta de conversaciones entre él y un personaje llamado Marcos sobre los temas más diversos, a veces ligeros, a veces serios. Aunque sea ante todo un animalito, Durito también es el intelectual en los comunicados y lleva a cuestas desde una pipa hasta una minimicrocomputadora. Al llamarlo 
don Durito de la Lacandona, Marcos lo transforma además en un caballero andante. Una tapita de frasco de medicina le sirve de escudo, un clip enderezado es su lanza, una ramita su espada, Excalibur. Media cáscara de avellana silvestre en su cabeza le sirve de casco y una tortuga —su corcel— completa su atuendo (DD 37, comunicado del 15 de abril de 1995). La asociación con don Quijore determina varios rasgos de su retrato, como su compromiso con los necesitados, su idealismo y su saber excéntrico.

El personaje de Durito lucha por emancipar a los marginados y es al mismo tiempo uno de ellos. No sólo ni siquiera pertenece a la especie humana sino que, como escarabajo, figura entre los más vulnerables de los animales. Cuando aparece por primera vez, está estudiando las estrategias del neoliberalismo en América Latina, pues quiere saber cuánto tiempo tomará hasta que el neoliberalismo sea vencido. Sólo entonces desaparecerán de la selva las botas de soldados y guerrilleros (DD 12, comunicado del 10 de abril de 1994). Más de dos ańos después, Durito anuncia la fundación de un círculo antibototas: "para cartas de admiración, solicitud de entrevistas, claveles y firmas de apoyo para la Sociedad Escarabajil Antibototas, favor de dirigirse a...) (DD 164, comunicado del 12 de octubre de 1996). Por otro lado, Durito está asociado con los libros y el conocimiento. Las partes didácticas de los comunicados —como las clases y conferencias que transmiten un mensaje político- son puestas sistemáticamente en su boca. En la figura de su personaje, Marcos ennoblece, por tanto, el saber de los que están en una situación ex-céntrica con respecto a los tradicionales centros del saber. Sin embargo, no sublima tal saber sino que lo relativiza al burlarse no pocas veces de Durito y al asociarlo con don Quijote.

Relacionando los textos sobre Durito con el contexto de la lucha zapatista queda claro que el escarabajo caballero andante representa a los guerrilleros. Como éstos lucha desde la marginalidad por el fin del neoliberalismo. Simultáneamente, de la misma manera que los indígenas y el Viejo Antonio, es representado como el depositario de un saber excéntrico. Pero en el caso de Durito la analogía con los indígenas sólo se establece por vía indirecta ya que, al contrario del Viejo Antonio, Durito no es un indígena. En las historias del insecto, el protagonismo de los indígenas en el contexto de la lucha zapatista no se corresponde con un protagonismo en el nivel de los textos. Que el marco de referencias en el libro sobre Durito sea menos exclusivamente étnico y local aún se deduce de otros factores. El tipo de intertextos que Marcos cita, por ejemplo. Mientras que los Relatos de el Viejo Antonio incluyen reescrituras de los mitos indígenas, en Don Durito de la Lacandona abundan los juegos inter- textuales con la flor y la nata del canon literario occidental. Veamos de qué tipo de intertextos se trata.

Entre las citas literarias, muchas aluden a la obra de Cervantes. La importancia de ésta se manifiesta de manera ejemplar en el personaje de Durito cuya asociación con don Quijote, un personaje que se volvió loco a causa de los libros, no es nada casual. En los textos sobre Durito, los personajes suelen ser lectores apasionados que están a menudo sumergidos en la lectura de un libro. En un relato, Marcos narra que Durito le ha traído de regalo un libro de Carlos Monsiváis (DD 91, 14 de enero de 1996), en otro, el escarabajo interrumpe a Marcos mientras que éste está leyendo a Brecht (DD 134, 5 de julio de 1996) y el propio Durito dice tener pasión por las novelas policíacas (DD 24, 17 de marzo de 1995). Este gusto que tienen sus personajes por la literatura refleja la afición del propio Subcomandante quien declaró que durante los primeros años en la selva no renía mucho que leer, pero que posteriormente fue abastecido de libros por simpatizantes enterados de su pasión por la lectura.

Sobre todo los que se ocupan de literatura han mostrado curiosidad por conocer las preferencias literarias de Marcos. Antes de que se lo preguntasen Gabriel García Márquez y Rafael Pombo (2001), el poeta argentino Juan Gelman le había preguntado qué escritores le gustaban más (1996). La respuesta de Marcos destacó, principalmente, que su gusto había evolucionado:

- La poesía que frecuentábamos nosotros era la que se consideraba poesía social o de compromiso. Que es la que nos gustaba, porque estábamos en eso. $\mathrm{O}$ la más lejana de los clásicos como Shakespeare, eso sí. Pero de la poesía contemporánea sólo la que tenía contenido social; la que no, nos parecía que no servía, que era contrarrevolucionaria, pequeñoburguesa, etcétera, etcétera.

- ¿Piensa lo mismo ahora?

-Evidentemente no.

¿¿Y qué piensa?

-Nos damos cuenta ahora que fueron esos elementos, los no esquemáticos, los no tradicionales respecto de esa cultura de izquierda en la que nos formamos, en especial de la izquierda clandestina, la de los subterráneos, los que nos abrieron ventanas. Que lo que nos salvó como proyecto social, como proyecto político $y$, sobre todo, como seres humanos fueron esas ventanas abiertas, esas supuestas "manchas" para un revolucionario cuadrado, lo que nos llevaba a nosotros a decir bromeando que para ser cuadros revolucionarios éramos bastante redondos. (Marcos citado por Gelman en La Jornada, 21 de abril de 1996) 
En esta entrevista, Marcos llama la atención sobre un proceso personal de desideologización y subraya que ha llegado a convencerse de que la literatura no debe procurar adecuarse a objetivos políticos porque el proceso de reducción estética en nombre de la verdad política no funciona necesariamente a favor de esta última. Sobre todo, parece sugerir que a sus preferencias literarias ya no las guían preferencias políticas. Examinemos sus alusiones literarias a fin de averiguar si esta afirmación es digna de fe.

En sus comunicados en general y en los relatos de Durito en particular, Marcos despliega un conocimiento literario bastante impresionante para un guerrillero. Intercala referencias a Dante y a Monsiváis, a Lewis Carroll y a Valle-Inclán, se refiere a la poesía de Miguel Hernández, Federico García Lorca, Fernando Pessoa, Charles Baudelaire y Paul Éluard, cita a dramaturgos como Shakespeare y Brecht, juega con la novela de caballería cervantina al mismo tiempo que alude a los personajes de las novelas policíacas de Vázquez Montalbán. Por tanto, hace alusión a autores de diversas nacionalidades, que escriben en diferentes idiomas y cuya fama no emana de simples motivos políticos. A primera vista, la lista parece confirmar el comentario de Marcos de que su aprecio por la literatura no se deja regir por normas políticas.

Sin embargo, una lectura que cuestione las apariencias de la heterogeneidad y vaya en busca de algún criterio que guíe la selección de los intertextos permite verificar que los autores citados han escrito críricamente acerca de la sociedad de su tiempo y que este compromiso ha sido asociado generalmente con una ideología progresista. Esto, que es evidente en los casos de los poetas de la república García Lorca y Hernández, de Éluard, Brecht, Cortázar, Benedetti, Galeano y Vázquez Montalbán, también puede decirse, aunque utilizando un vocabulario más en consonancia con la época en que vivieron, de Cervantes y de Dante. Todos ellos son conocidos por una actitud crítica, un compromiso político o social notorio en contra del establishment o del statu quo, por lo que se puede decir que las referencias intertextuales funcionan como un mecanismo de unificación ideológica de los relatos.

Pero una notable excepción funciona como contrapeso y contribuye a hacer que la ideología sea menos visible. En diversas ocasiones Marcos expresa su admiración por Jorge Luis Borges. ${ }^{4}$ Este intertexto de un escritor a menudo percibido como políticamente conservador confirmaría lo dicho por Marcos

4 Comunicado del 28 de mayo de 1994 en ezLn 1994: 239; Comunicado del 16 de enero de 1995 en ezLn 1995: 200; Comunicado del 14 de marzo de 1995 en EzLN 1995: 274; Discurso sobre el carácter no político de sus preferencias literarias y la índole abierta de su propio lenguaje. En cierto momento, dice al final de una asamblea pública: "Pudiera parecer extraño que haya traído yo, juntos, a poetas nahuas, al Popol Vuhy a Jorge Luis Borges para esta clausura. Sobre todo por Borges" (2000: 172, discurso de agosto de 1996).

En primer lugar, el comentario formula una hipótesis acerca del horizonte de expectativas que Marcos atribuye a sus lectores ya que dice que éstos no esperan referencias a Borges y que, por consiguiente, esperan escuchar un discurso ideológico. Al mismo tiempo, la expresión "pudiera parecer extraño" sugiere que Marcos transgrede este horizonte de manera consciente, construyéndose un autorretrato alternativo de un guerrillero cuyo lenguaje es abierto, literario, y no ideológico. Además, las citas de Borges también dicen algo sobre la ideología que Marcos atribuye a sus lectores. Citando a Borges, demostrando de esta manera el carácter no ideológico de su discurso, Marcos muestra que piensa que sus lectores son sensibles a la doxa del fin de las ideologías y que incluso un guerrillero, crítico frente a muchos aspectos de la ideología dominante de su sociedad, si quiere ganar adeptos, debe plegarse a esta doxa.

Por otra parte, las alusiones a Borges son más que una mera estrategia ya que, en calidad de intertexto estructural, contribuyen a poner de relieve algunos de los principales temas e ideas de Marcos. La presencia de Borges puede leerse como una clave interpretativa mediante la cual el Subcomandante llama la atención sobre las coincidencias que existen entre la obra borgiana y la suya. Quien lea los relatos a partir de esta clave descubrirá que, de la misma manera que el escritor argentino, el guerrillero se crea un personaje detrás del cual se disimula; con él comparte un gusto por lo clandestino y la mistificación. Como veremos más adelante, sus aurorretratos muestran que, de la misma manera que Borges, considera que el escritor es un humilde redactor y como él practica la escritura como una lucha contra los géneros establecidos, como reivindicación de la parodia y transgresión el canon. La figura de Durito que declama pasajes enteros del Quijote, reclama la autoría de la obra de Brecht y cambia constantemente de identidad, la omnipresencia de la ironía y la intertextualidad en los comunicados, la recurrencia de la imagen del espejo y la importancia en la guerrilla zapatista de la letra impresa despiertan sin cesar ecos hacia la obra

en Defensa del Patrimonio Cultural de agosto de 1996 en subcomandante Marcos 2000: 160 y 172. 
borgiana. Mediante sus alusiones a Borges, Marcos también ha dado pie a que sus relatos sean leídos según claves de lectura posmodernas.

La subversión paródica de algunos grandes relatos de la historia mexicana a su manera ha dado pie a que se calificara la prosa de Marcos de posmoderna. El narrador presenta a Durito mediante una breve comparación: «Durito tiró de las riendas y rayó su caballo como cuando Pancho Villa tomó Torreón» (DD 42, comunicado del 15 de abril de 1995). La asociación del escarabajo con Pancho Villa teje un lazo discursivo entre el EzLN y la Revolución mexicana. Pero si tomamos en cuenta que Pancho Villa es uno de los héroes más intocables en el panteón de los revolucionarios mexicanos, resulta descarado asociarlo con un insecto un poco loco y sabelotodo. La construcción del personaje se hace cada vez más insolente como cuando Don Durito, en busca de un caballo, pone los ojos en una tortuguita que bautiza con el nombre irónico de Pegaso :

Durito ha escrito en el caparazón de la tortuga, con letra grande y decidida: "PEGASO. Copy Rights Reserved». Y, abajito, «Favor de abrocharse los cinturones". [...] Después de unos minutos, puedo leer en el flanco izquierdo de Pegaso "Sección de Fumadores" "Prohibido el paso a charros sindicales" "Espacio libre para anuncios. Informes en Durito's Publishing Companym. Yo creo, sin embargo, que no hay ya mucho espacio libre, el anuncio ocupa todo el flanco izquierdo y la retaguardia de Pegaso. (DD 39, comunicado del 15 de abril de 1995)

La desacralización afecta, pues, también al caballo de Pancho Villa, lo cual carecería de importancia si no fuera porque los caballos, consagrados por la Revolución mexicana como parte del mito del héroe, siguen siendo un símbolo didáctico e ideológico en la historiografía posrevolucionaria.

Las parodias de los símbolos revolucionarios abundan en los relatos de Durito. Con su irreverencia habitual, éste transforma el lema del secretario de Estado José Vasconcelos «Por mi raza hablará el espíritu» en la fórmula de despedida «Por mi raza hablará el rock» (DD 59, comunicado de mayo de 1995). Esta parodia es tanto más significativa cuanto el lema de Vasconcelos ha llegado a ser una de las frases fundacionales del ideario posrevolucionario oficial que, hasta la actualidad, es el lema oficial de la Universidad Nacional Autónoma de México. Proclama que las distintas razas deben fundirse y que este mestizaje constituirá el fundamento de la raza latinoamericana, será la garantía de su futuro espíritu. Al burlarse de ella, Marcos desenmascara el uso que la retórica oficial hizo de los escritos de Vasconcelos y apunta a la distancia que separa esta retórica y la realidad, que mide entre la inclusión del aporte indígena en el discurso sobre el mestizo y su exclusión en la práctica. La sustitución de la palabra espiritu por rock traduce, además, una aspiración de desplazar a la alta cultura que es el privilegio de una élite por las formas de cultura más populares y accesibles.

Al proponer al Viejo Antonio y a Durito como emblemas literarios del EzLN, Marcos invita a que se hagan dos lecturas de la lucha zapatista, una centrada en la roots dimension, otra en la routs dimension (Paul Gilroy citado en Childs y Williams 1997: 45). La dimensión de las raíces, de la identidad adquirida, está representada de manera eminente en los relatos del Viejo Antonio que giran esencialmente en torno a los pueblos autóctonos de México. La routs dimension, la del viaje incansable, es representada por Durito que no está nunca en reposo, cuya identidad reside en una búsqueda permanente y que, en calidad de caballero andante, prueba su suerte como espalda mojada en EE UU. y visita el D. F. como turista de la provincia. Ambos personajes también dejan constancia de la diversidad de lenguajes sociales - a veces contradictorios- absorbidos y transformados en los relatos, como los del México posrevolucionario, del indigenismo, de las subculturas contestatarias y de la posmodernidad occidental. De esta manera, aparte de que dan cuenta, cada uno a su manera, de diversos aspectos de la lucha zapatista, el Viejo Antonio y Durito permiten que varios tipos de lectores se identifiquen con el EZLN.

\section{ELÍAS}

Desde esta perspectiva, Elías Contreras es una síntesis de Durito y del Viejo Antonio, pues es al mismo tiempo un indígena y un viajero que hace un largo viaje al D. F. Uno de los aspectos más innovadores de Muertos incómodos, la novela donde hace su aparición como protagonista, lo concierne. El personaje indigena, en la literarura policíaca generalmente imaginado en un papel de víctima o de culpable porencial, ha dejado de pertenecer al bando de los malvados y mentirosos para pasar a representar la justicia (Ponce 2007: 74). Pero a pesar de que, desde el punto de vista actancial, Elías desempeña un papel innovador, la innovación es truncada porque su construcción como personaje es tributaria de algunos estereotipos tradicionales del indígena. Veamos por qué.

En los textos sobre el Viejo Antonio, el espacio narrativo era la Selva Lacandona. En Muertos incómodos, desde el quinto capítulo Contreras investiga en el Distrito Federal. Esto conlleva una diferencia flagrante de la imagen 
de Contreras frente a su antecedente literario. Marcos había ubicado a Antonio en su medio natural, lo cual le permitía retratarlo como un personaje sabio. Al contrario, a Contreras lo describe como un hombre primitivo que no está familiarizado con los objetos del mundo industrializado, ni con las costumbres en la ciudad moderna. El primer contacto de Contreras con la ciudad sugiere que el chiapaneco no sabe que las calles tienen nombres o que existen edificios tan altos:

Se me afiguró que los ciudadanos tenían también su modo y que viendo las antenas podian saber onde mero quedaban las casas. Después supe que no, que ellos tienen calles con nombres y números y aluego pos hay casas altas, muy altas, como si quisieran estarse arriba de las antenas, y entonces le ponen número tam-

bién a cada pedazo de casa. (Cap. III, p. 16)

Mientras que los comentarios del Viejo Antonio sobre los animales y las plantas lo sitúan en una larga tradición literaria de jefes indigenas sabios, las afirmaciones que Contreras hace sobre la ciudad de México lo presentan más bien en la tradición popular del primitivo en la gran metrópoli. Este aspecto del personaje desdice su función actancial que le confiere responsabilidad y saber y entra en contradicción con las declaraciones de Marcos que presenta a los indígenas como hombres modernos, familiarizados con la cultura mestiza. Armando Bartra escribió en su prólogo sobre los relatos del Viejo Antonio que le gustaban éstos porque daban cuenta de la hibridez de la cultura indígena chiapaneca en la que «la cultura tradicional de estirpe maya se entrevera con cumbias, películas de Pedro Infante e historietas concientizadoras de Rius" (1998: 12). La mirada primitiva con la que Contreras descubre la ciudad es incompatible con esta descripción.

La lengua que el autor pone en boca de Contreras refuerza el primitivismo del personaje. En los relatos del Viejo Antonio, Marcos había intentado integrar un eco de las voces indígenas. Los recursos que utilizó para este fin, aunque quizás no lograran producir fieles transposiciones de las lenguas mayas, daban cierta impresión de autenticidad a la lengua del Viejo Antonio y demostraban un esfuerzo por recrear de manera poética una visión mitológica del mundo. Aunque volvemos a escuchar algunas de estas deformaciones lingüísticas en boca de Contreras, el resultado es distinto. Los dos o tres tics de Contreras y la insistencia con que los usa, incluso si puede que sean representativos del habla de los indígenas chiapanecos, afean su lengua. Una de estas marcas es la reperi- ción fastidiosa de "o sea" y "que sea» que, por una parte, presenta la lengua de Contreras como testimonial y denotativa, pero que, por otra parte, molesta en la lectura. La cita siguiente es representativa del idiolecto del investigador:

Fue un poco bastante difícil. Que sea moverse en el monstruo. Seguido se me iba otra vuelta al pesero, que sea la combi, que sea el microbús. O sea que por estar pajareando se me iba hasta tres vueltas la combi [...] El otro día andaba yo vuelteando por el Monumento a la Revolución, que sea que estaba reconociendo el rerreno. Que sea para saber pá donde correr, que sea por si se ponía brava la cosa o el caso, según. (Cap. vir, p. 30)

Ya que Contreras se expresa en un español deficiente, Belascoarán no deja de corregirlo, como don Quijote a Sancho Panza. También como Cervantes, Marcos una y otra vez tiene la precaución de desarmar a sus críticos potenciales siendo él el primero en criticarse. Para ello, pone en labios de sus personajes excusas que serían mucho menos aceptables si vinieran de él mismo. Esta estrategia, que ya aparece en los relatos, reaparece en la novela cuando un personaje afirma que prefiere escuchar a Contreras que a Marcos porque entender a éste es dificil:

Me gustó mucho su palabra porque le entendí todo. Sí, es que a veces los comunicados del Sup son muy complicados, como que no se entienden porque a veces usa palabras muy elevadas. En cambio Elías habla así como nosotros. (Cap. xI, p. 50)

En esta cita, Marcos se critica a sí mismo como autor de los comunicados y se elogia a sí mismo como inventor del personaje Contreras y, especialmente, como creador de su habla. La cita también sugiere que el objetivo de Marcos al hacer hablar a Contreras de esta manera es acercarse a los lectores más humildes. Pero cabe preguntarse si de esta manera no se aliena a una parte de su público culto, que constiruye el público lector principal de la novela.

La identidad de Elías Contreras podría hacer creer que, a la manera de los relatos del Viejo Antonio, en Muertos incómodos el grupo étnico de los indígenas aparece en calidad de sujeto y beneficiario principal de la acción. No obstante, aunque haya otros personajes indígenas en la novela, no importa mucho para la trama si un personaje es o no es indígena, lo cual significa que el tema de la identidad étnica y de la discriminación racial ha perdido su preeminencia anterior. A esta conclusión se podría objetar que al inicio de la novela aparece 
una indígena en un papel tradicionalmente indígena a quien se le niega el derecho de hablar en público: antes de que Contreras asuma la responsabilidad de investigar a Morales, Marcos le encarga una investigación acerca de una indígena desaparecida. Ésta se «autodesapareció» porque su marido zapatista la maltrataba y no quería que fuera una de las responsables en un colectivo de mujeres zapatistas. Si es verdad que esta historia inicial es protagonizada por una indígena discriminada, no se la presenta como vícrima de una polírica racista, sino que es reducida al silencio público por ser mujer. Al tratarlo al principio de su novela, Marcos da una visibilidad especial al problema de la discriminación que sufre la mujer indígena, tema prominente en el discurso zapatista desde que lo seńaló en 1993 la Ley Revolucionaria de Mujeres. La manera de presentarlo sugiere que entre los zapatistas sigue habiendo resistencia por parte de los hombres a la hora de tratar a la mujer en pie de igualdad.

En Muertos incómodos también aparecen otros personajes cuya caracterización incluye un importante componente de género. En el D. F., a Elías Contreras lo salva una hermosa nińa que luego resulta ser niño, la transexual Margarita que trabaja en la prostitución y que se convierte en la aliada del investigador. Se explica ante Contreras en una arenga moralista:

Entonces una, o uno, tiene que esconder su diferencia o arrinconarlo en una calle oscura. ¿Y por qué vamos a esconder lo que somos? Trabajamos como cualquiera, amamos y odiamos como cualquiera, sońamos como cualquiera, tenemos virtudes y defectos como cualquiera, o sea que somos iguales pero diferentes [...] Además, ¿no se usa la referencia homosexual para insultar a alguien? «Puto», "marimacha", "mampo", "mariposón". Bueno, pero qué te cuento a ti si «indio" sigue siendo todavía un insulto en este país que se construyó y se levantó sobre las espaldas de los indígenas. (Cap. Ix, p. 38)

Margarita se identifica con los indígenas porque también éstos son víctimas de burlas y de agresión física, y culpados de los peores crímenes únicamente por ser distintos. No obstante, en la novela la discriminación sufrida por cuestiones de género es más prominente que la discriminación étnica.

\section{MARCOS}

Aunque desde 1994, el Subcomandante se ha beneficiado de una enorme adhesión, siempre ha tenido oponentes. Entre éstos destacan Maite Rico y
Bertrand de la Grange quienes, en Marcos, la genial impostura (1998), lo retratan como un mestizo oportunista que siembra el miedo entre los indígenas y que se aprovecha de ellos para aumentar su prestigio y poder personales. En sus comunicados, los zapatistas han replicado una y otra vez a estas acusaciones, sosteniendo que los verdaderos jefes son los indígenas mientras que Marcos es sólo un subcomandante, un subalterno en sus filas, útil para asegurar la comunicación entre dos instancias que no emplean la misma lengua, ni lingüistica ni culturalmente hablando. Dado el carácter polémico del tema, es lógico leer los autorretratos de Marcos en las historias del Viejo Antonio, en los relatos de Durito y en Muertos incómodos como sendas versiones literarias acerca de su papel entre los zapatistas.

Mientras los relatos de Durito y del Viejo Antonio se diferencian por el tono, el origen de los intertextos y la lengua, se apoyan en un reparto de los papeles básicamente idéntico. En calidad de narrador, el Viejo Antonio es al mismo tiempo un transmisor que transmite los relatos que le contó su padre don Antonio o los dioses primeros quienes "Por los sueños nos hablan y nos enseñan" (VA 78). De esta manera se establece una delegación de voces entre don Antonio, el Viejo Antonio y el yo:

Cuenta el viejo Antonio que cuando era joven su padre don Antonio le enseñó a matar al león sin arma de fuego. Cuenta el viejo Antonio que cuando era joven Antonio y su padre era el viejo Antonio le contó la historia que ahora me dicta al oído para que la mar la conozca de mis labios. (VA 123)

Esta cita, que es la narración marco de uno de los relatos, pone en escena al destinatario de los relatos contados por el Viejo Antonio. Se trata de un yo anónimo cuya fisonomía es más bien indefinida. Ésta es, precisamente, una de las indicaciones que llevan a identificarlo con el Subcomandante. Como Marcos, el yo no tiene nombre ni rostro y como Marcos, funciona como puente ya que debe transmitir las palabras del Viejo Antonio a su vez a una audiencia externa.

Llama la atención que el yo casi siempre funcione como oyente frente al Viejo Antonio y que, cuando habla, suela ser para preguntar. Esta repartición de los papeles se desprende de la conjugación de los verbos de expresión. Mientras que los verbos que pertenecen al campo semántico del saber llevan como sujeto sintáctico al Viejo Antonio, los que indican la demanda de información van sistemáticamente asociados con el narrador principal. Ya cuando éste aparece por 
primera vez, leemos: "Me contó el Viejo Antonio", «Le pregunté», «Me enseńó" $y$ "me dijo» (VA 22). La edad de los dos personajes refuerza esta jerarquía, pues es fácil asociar la vejez del anciano con la sabiduría. Al revés, el yo aparece como joven que aún debe aprender muchas cosas. La relación entre maestro y discípulo que caracteriza el intercambio de palabras se reproduce en el terreno de los actos no verbales ya que el yo se retrata como un torpe que se beneficia de la ayuda del indígena. En un relato en el que el yo y el Viejo Antonio persiguen a los venados y se ven cercados por la noche, el yo toma la iniciativa para encontrar el camino de regreso:

Tenemos que encontrar el camino de regreso - me escucho decir, y agrego: - Traigo brújula - le digo yo como si dijera «tengo móvil, por si quieres un aventón». - Sí pues — dice de nuevo el Viejo Antonio como dejándome la iniciativa y mostrándose dispuesto a seguirme.

Yo recojo el desafio y me declaro dispuesto a hacer gala de mis conocimientos guerrilleros de dos años en montaña. Me arrincono bajo un árbol. Saco el mapa, el altímetro y la brújula. Como hablando en voz alta, pero en realidad alardeando frente al Viejo Antonio, describo alturas sobre el nivel del mar, cotas topográficas, presión barométrica, grados y milímetros, puntos visados y otros etcéteras de lo que los militares llamamos «navegación terrestre». (VA 103)

Tras caminar un buen rato, el yo mira con vergüenza al Viejo Antonio quien toma la iniciariva y encuentra el camino sin ningún esfuerzo. El relato - una alegoría sobre cómo los pueblos indígenas pueden encontrar su lugar en la historia-interesa aquí porque permite demostrar que se reproduce una y otra vez la relación de dependencia entre el sabio Antonio y el ignorante yo.

Marcos hubiera podido escribir los relatos contados por el Viejo Antonio sin una narración marco, pero entonces hubiera perdido la posibilidad de integrar el principio del diálogo didáctico, lo cual le ha permitido a su vez escenificarse a sí mismo como transmisor de los mensajes indígenas, in casu las historias del Viejo Antonio. Esta estructura reproduce uno de los mensajes en los comunicados zapatistas: el Subcomandante no es sino un intermediario, un traductor de los mensajes de los indígenas. La narración marco aún realza un segundo rasgo de Marcos. Éste habría podido silenciar su condición de mestizo oriundo de la ciudad. Sin embargo, optó por resaltarla. Al ubicarse a sí mismo como forastero en la selva - difícil de penetrar, donde casi siempre llueve y hace frí- introduce en sus textos un tema frecuente en la novelística latinoamericana, el de la estancia de un chapucero extranjero guiado por un nativo en un paisaje no familiar. Este tema le permite dar un nuevo contenido a los rasgos que sus adversarios utilizan para demostrar que carece de la condición de pobre y marginado y que, por tanto, no puede representar legítimamente a los indígenas. En un contexto de selva tropical, el hecho de que sea licenciado y que venga de la ciudad estorba y lo transforma en un subalterno entre los subalternos, incluso lo margina en segundo grado ya que hace que dependa y aprenda de ellos. De esta manera, la narración de su carrera tiene características de un Bildungsroman. En la jungla, Marcos no es una autoridad que victimiza a los desposeídos, sino que su suerte está en las manos de éstos.

También en los textos de Durito el diálogo es un principio constituyente. El escarabajo caballero andante no tarda en asignarse a sí mismo un escudero, un Sancho Panza, el SupMarcos. Una vez más, el guerrillero Marcos, autor y narrador, se retrata a sí mismo como personaje e interlocutor. En el personaje que le corresponde destaca un rasgo que lo acerca al personaje del yo en los relatos del Viejo Antonio: frente a don Durito de la Lacandona, Sancho Panza/ SupMarcos ocupa una posición subordinada. De hecho, Marcos vuelve a intensificar la subordinación del personaje. En calidad de escudero, debería servir a su amo; sin embargo y por el contrario, le ruega constantemente a Durito que le ayude. A una de estas súplicas, Durito contesta: «Yo, señor mío, soy un caballero andante, y los caballeros andantes no podemos dejar de socorrer al necesitado, por más narizón y delincuente que sea el desvalido en cuestión" (DD 53, comunicado de mayo de 1995). Tal y como el yo en los relatos del Viejo Antonio era subalterno en segundo grado, el SupMarcos/Sancho Panza es doblemente dependiente.

Aunque sea de otra forma, el Subcomandante vuelve a autorretratarse como un antihéroe. Si en el contexto de la selva tropical Marcos es el personaje que pierde el rumbo y no puede con la lluvia, en un contexto de referencias librescas y de juegos literarios su imagen corresponde unas veces a la del escudero y otras a la del profesor despistado. Siempre anda absorto en sus pensamientos (a menudo está pensando en la luna), no logra respetar las fechas límite que le ponen los periódicos o los organizadores de coloquios (entonces Durito debe echarle una mano), es un verdadero dormilón y además narizón. Durito se basa en este último rasgo para establecer comparaciones con Cyrano de Bergerac, anotando, sin embargo, que éste tenía mejor pluma (DD 124, comunicado del 6 de abril de 1996; DD 153, comunicado del 18 de septiembre de 1996).

Conociendo las críticas que el papel de Marcos ha suscitado, es legítimo leer los personajes del yo en Relatos de el Viejo Antonio y de Sancho Panza en 
Don Durito de la Lacandona como respuestas del Subcomandante a sus críticos. Puesto que dichos personajes están en una situación de dependencia, en ellos intenta acercar discursivamente el lugar desde donde él mismo habla a los indígenas cuyos mensajes dice traducir. Esta interpretación del yo y del supMarcos/ Sancho Panza también permite establecer cierta analogía entre estos personajes literarios y el pasamontańas. Respectivamente en el nivel discursivo y físico funcionan como disfraces con los que Marcos desvía la atención de su verdadera identidad al escamotear sus rasgos superiores que lo distinguen de los zapatistas indígenas. En este sentido, los textos literarios ilustran que Marcos aspira a ser visto como marginado entre los marginados. En las filas zapatistas, así lo sugiere Marcos, no son los indígenas los que toman como ejemplo a los mestizos, sino al revés, son los mestizos los que quieren adaptarse a los indígenas.

Pero los relatos, sobre todo aquellos donde aparece Durito, permiten avanzar otra interpretación con respecto al tema de la autoría de Marcos. Durito no sólo se presenta como don Quijore y Marcos no sale únicamente disfrazado de Sancho Panza o de interlocutor del Viejo Antonio. Conforme los textos se publican, las identidades se multiplican y se borran, con lo cual Marcos también acaba por ofrecer imágenes literarias a veces contradictorias de su identidad. Con ocasión de la apertura del «Primer Encuentro Intercontinental por la Humanidad y contra el Neoliberalismo" Marcos se dirigió a su público con las palabras siguientes:

Buenas cardes a todos. Hemos llegado un poco tarde y les pedimos que nos disculpen, pero es que nos hemos topado con unos gigantes multinacionales que nos querían impedir llegar. El mayor Moisés nos dice que son molinos de vienro; el comandante Tacho dice que son helicópteros. Yo les digo que no les crean: eran gigantes. (Citado en Vázquez Montalbán 1999 s. p.)

En esta cita, Marcos se asigna a sí mismo el rol de don Quijote. En otro momento se convierte en boca de Durito en "mi querido Guatson" (DD 75, comunicado del 17 de julio de 1995; comunicado de septiembre/octubre de 1995) o "Whatson Sup" (DD 18, comunicado del 11 de marzo de 1995). Esto haría pensar que Durito se presentaría como Sherlock Holmes. Pero una vez más los papeles se mezclan ya que Durito no es Sherlock Holmes, sino que éste es un antiguo alumno del escarabajo quien se sorprende del hecho de que "Jolms" haya llegado a ser un personaje literario famoso. También Bertolt Brecht se hizo famoso gracias a Durito quien, siendo el verdadero autor de la obra del escritor alemán, en honor a él hace como si los dos la hubieran escrito juntos (DD 33, comunicado del 4 de abril de 1995; DD 137, comunicado del 5 de julio de 1996). Marcos advierte en cierto momento a Durito: "Creo que te están confundiendo los tiempos y las novelas" (DD 33, comunicado del 4 de abril de 1995). A esta crítica, Durito opone su propia visión lamentando que Marcos no la pueda compartir ya que no conoce la teoría de Umberto Eco sobre la opera aperta (DD 91, comunicado del 14 de enero de 1996). Además de ser un adepto de dicha teoría, Durito está convencido de que la naturaleza imita al arte (DD 67, comunicado del 30 de junio de 1995), una afirmación que confirma la función prioritaria de los signos en la guerrilla zapatista.

La confusión entre personajes y voces, y el cuestionamiento de la función del autor en los textos sobre Durito son elementos que inducen a ver a los personajes creados por Marcos, y sobre todo a aquellos que le corresponden a él mismo, en relación con la índole intercambiable y fluctuante de las identidades individuales en las filas zapatistas. Entre los guerrilleros, cada uno es todos y todos son cada uno, no importa Marcos ya que no importa quién presta su voz a la comunidad. De nuevo podemos relacionar estas interpretaciones con la imagen del pasamontańas. Sería, entonces, un signo de la falta de trascendencia de la voz individual en el ejército zapatista y de la identidad plural y poco significativa de Marcos.

Cuando Marcos vuelve a aparecer como narrador y como personaje en Muertos incómodos, es sin disfraces. En comparación con los relatos sobre el Viejo Antonio y el escarabajo Durito, su voz directa se oye relativamente poco, por cuanto el narrador principal es Elías. Igualmente en calidad de personaje es bastante menos protagónico que en sus relatos anteriores. Esto hace pensar que ha cumplido la promesa de disminuir su visibilidad a favor de los dirigentes indígenas, una intención que éstos ya habían anunciado de manera programática en 1995 :

La necesidad de un traductor entre la cultura indígena zapatista y la cultura nacional e internacional provocó que la obvia nariz, además de estornudar, hablara y escribiera. Todos ustedes estarán de acuerdo con que lo hizo y en demasía. [...] Fue éste el error que tardamos en ver y que reconocimos en la celebración del 17 de noviembre de 1994. [...] Los protagonistas reales serán ahora los protagonistas formales. La nariz pronunciada volverá a estornudar más y a hablar menos. (Comunicado del 11 de mayo de 1995, en EzLN 1995: 333-334) 
Empero, la disminución de la visibilidad del personaje Marcos y el hecho de que se escuche menos como narrador corren parejas con una evolución contraria en su papel como personaje que, de subalterno en los relatos del Viejo Antonio y Durito, se hace más autoritario. Una comparación permite ilustrar este cambio.

Hemos visto que, en los relatos, Marcos siempre se presenta de manera cuidadosa en una posición subordinada frente al Viejo Antonio y a Durito. En Muertos incómodos, al contrario, el nuevo personaje literario que Marcos se creó a su medida desempeńa un papel de dirigente-remitente desde el primer capítulo. Ahora explica, enseña y manda a los otros, especialmente a Contreras. Marcos es el sujeto de las frases, mientras que el complemento objeto indirecto y receptor de sus mensajes es el zapatista indígena. La novela abre con la frase: "Todo lo que tarde más de seis meses, o es un embarazo o no vale la pena" A SÎ [sic] ME DIJO EL SUP» (cap. I, 1; en mayúsculas en la novela). Por otra parte, si el indígena Contreras toma la palabra frente al Sub, es para preguntar: "Le pregunté al Sup que cuánto tiempo tengo y él me dijo que tres días nomás. Yo no le pregunté por qué tres días y no uno o diez o quince. Él lo sabrá» (ibídem). Aparte de un solo episodio que lo retrata como chapucero y un fragmento en el que aparecen los zapatistas indígenas Esther y David como los que saben y Marcos como el que formula las preguntas, ahora éste se ha convertido en un mando en la Selva desde donde mueve los hilos y ordena a los demás. En sus textos de ficción, de una posición subalterna en la narración se ha desplazado hacia una posición de jefe, exactamente lo contrario de lo que afirmaron los zapatistas en cuanto al contexto a lo largo de sus declaraciones.

\section{Conclusión}

Tras estudiar las literaturas centroamericanas, Beverley y Zimmerman llegaron a la conclusión de que las luchas políticas y los combates por la liberación nacional provocan cambios sociales que, a su vez, entrañan la creación de nuevas formas de literatura y, más específicamente, ejercen presión sobre el sistema de los géneros literarios (1990: 172). Los nuevos contextos políticos habrían hecho que la poesía, un género literario privilegiado en Centroamérica, perdiera su preeminencia frente a un nuevo género, el testimonio. Por su parte, el contexto de los años noventa habría estimulado nuevas formas de literatura no testimoniales. Nuestro análisis de los textos del Subcomandante Marcos aporta elementos a favor de esta tesis.

Por un lado, existe un consenso relativamente grande sobre el carácter novedoso de la lucha zapatista, sobre todo por su desinterés hacia el poder y su voluntad de buscar soluciones mediante un diálogo con la sociedad civil. Su índole inusual parece haber ejercido una presión sobre el sistema de los géneros discursivos, pues apareció la posdata como género dentro del comunicado guerrillero y se literaturizó un discurso en principio político, con lo cual surgió una alternativa frente a la más tradicional politización de la literatura. En este sentido, los relatos sobre Durito, por ejemplo, no sólo son lo que sostiene Armando Bartra, un pastiche de la novela de caballería (1998: 12) sino que, de la misma manera en la que Cervantes reescribió viejos géneros parodiándolos, los relatos de Marcos parodian y se alejan de la tradicional literatura comprometida en América Latina en la medida en que ésta era dogmática y mesiánica.

Su naturaleza postideológica se detecta por ejemplo en las reiteradas críticas a las que se someten los macrorrelatos de las vanguardias de izquierda y que el narrador delega sobre todo en Durito:

El problema de la revolución (ojo con las minúsculas) pasa de ser un problema de LA organización, de EL método, y de EL caudillo (ojo con las mayúsculas), a convertirse en un problema que atañe a todos los que ven esa revolución como necesaria y posible, y en cuya realización todos son importantes. (1999: 57, comunicado de mayo de 1995)

Otro pasaje, también en boca de Durito, desenmascara como falsas las oposiciones ideológicas tradicionales. Refiriéndose a los «Maquiavelos modernos», Durito rechaza el valor operacional de éstas:

Y aquí aciertan, pero sólo en lo que se refiere a que la relación entre ética y políica no es un asunto fácil de resolver con la definición de bandos: malos versus buenos. (1999: 100, comunicado del 14 de enero de 1996)

Los textos de Marcos de los años noventa extraen su legitimidad en gran medida de ese juego posicional frente a las ideologías tradicionales. A pesar de que los relatos en el fondo sean a veces tan ideológicos como cualquier discurso político - los aspectos etnocéntricos de los relatos del Viejo Antonio y el criterio ideológico de las referencias intertextuales en Durito lo demuestran - su autor se ha esforzado por evitar que se lean así. 
Cuando Marcos reaparece en la escena literaria en 2004, es como novelista. De manera interesante, la vuelta a un género más tradicional se acompaña de una normalización del discurso que reanuda con las tradicionales oposiciones ideológicas. En comparación con los relatos anteriores, Muertos incómodos es pragmático y tiende a reducir al máximo las ambigüedades. Mientras que, en los relatos, Marcos utilizaba mayúsculas para poner de relieve la índole esencialista con la que algunas palabras se utilizaban entre izquierdistas dogmáticos, en la novela las emplea sin esas marcas de distanciamiento. Un personaje zapatizante dice: «EL asesino es el sistema. El sistema sí. Cuando hay un crimen hay que buscar al culpable arriba, no abajo. El MAL es el sistema y los MALOS son quienes están al servicio del sistema" (cap. III, p. 14). En Muertos incómodos los personajes se clasifican en dos paradigmas, con lo cual no sólo aparecen conceptos — como derecha e izquierda - cuyo valor operacional se había cuestionado en los relatos, sino que además aparecen en una relación de oposición radical de buenos versus malos. Un personaje zapatizante, campamentero italiano, divide a los extraterrestres en dos categorías:

Los malos, dice, ya aterrizaron hace tiempo en Washington, Londres, Roma, Madrid, Moscú, México y tornaron el poder e impusieron la moda del 'fastfood'.

Y los buenos... bueno, los buenos no han aterrizado todavía, pero si en algún lugar van a aterrizar, es en suelo zapatista. (Cap. mI, p. 11)

Mientras que en los relatos sobre don Durito y el Viejo Antonio, este tipo de afirmaciones binómicas alternaban con otras más críticas que las cuestionaban o que intentaban escamotearlas, en la novela sólo queda lo ideológico. Es verdad que se trata de puntos de vista expresados por personajes literarios, por lo cual no se los puede asignar automáticamente a su autor. Empero, son representativos de los textos en los que aparecen y de esta manera dan cuenta de una ideologización abierta de la escritura de Marcos quien parece haber abandonado su prudencia anterior a favor de un lenguaje más duro.

Según la tesis de Beverley y Zimmerman, la nueva normalización del sistema de géneros y la concomitante vuelta a un discurso más tradicional serían el signo de transformaciones en las luchas sociales. Ahora bien, paralelamente con otros cambios ocurridos después del 11-S, las tomas de posición propiamente políticas del EZLN se han en efecto endurecido. Partiendo de la imagen que el propio Subcomandante utilizó para hablar de su prosa — un arma dirigida al corazón de los lectores-, se podría pensar que uno de los elementos de la metáfora ha sufrido una transformación: sea el arma, el tipo de discurso utilizado por Marcos para realizar sus objetivos, sea la percepción que éste tiene del corazón, la composición o las expectativas de su público lector. 


\section{Bibliografía}

Ashcroft, Bill; Grifriths, Gareth; Tiffin, Helen (1989): The Empire Writes Back. Theory and Practice in Post-colonial Literatures, London/New York: Routlegde.

BarTrA, Armando (1998): «Mitos en la aldea global», en Subcomandante Insurgente Marcos: Relatos de el Viejo Antonio, Chiapas: CIACH, pp. 7-17.

Beverley, John; Zimmerman, Marc (1990): Literature and Politics in the Central American Revolutions, Austin: University of Texas Press.

Childs, Peter; Williams, Patrick R. J. (1997): An introduction to Post-Colonial Theory, London: Prentice Hall; Harvester Whearsheaf.

Debray, Régis (1995): "A demain, Zapata ", en Le Monde, 23 de marzo.

DE lA GARZA, Mercedes (ed.) (1980): Literatura maya. Caracas: Biblioteca Ayacucho.

De la Grange, Bertrand; Ruco, Maite (1998): Marcos, la genial impostura, México: Aguilar.

DE Vos, Jan (2002): Una tierra para sembrar sueños. Historia reciente de la Selva Lacandona 1950-2000, México: FCE, CIESAS.

EZLN (1994): Documentos y comunicados 1, México: Era.

- (1995): Documentos y comunicados 2, México: Era

FAVre, Henri (1998): El indigenismo, México: Fondo de Cultura Económica.

García Márquez, Gabriel; Pombo, Rafael (2001): «Habla Marcos», en El País, 25 de marzo, pp. 6-7.

Gelman, Juan (1996): "Nada que ver con las armas", en La Jormada, 21 de abril.

LE Bot, Yvon (1997): Subcomandante Marcos. El sueño zapatista, Barcelona: Plaza y Janés.

Lienhard, Martín (2003): La voz y su huella, México: Casa Juan Pablos/Universidad de Ciencias y Artes de Chiapas.

PAZ, Octavio (1994): "Chiapas: hechos, dichos, gestos», en Vuelta, n. ${ }^{\circ} 208$, pp. 55-5.
Ponce, Néstor (2007): «Subcomandante Marcos - Paco Ignacio Taibo II: los otros círculos del detective en Muertos incómodosm, en La novela policiaca contemporánea en América Latina, Aleph, n. ${ }^{\circ} 2002$, pp. 71-78.

Subcomandante Marcos (1998): Relatos de el Viejo Antonio, Chiapas: CIACH.

- (1999): Don Durito de la Lacandona, Chiapas: CLACH.

- (2000): Detrás de nosotros estamos ustedes, Barcelona: Plaza y Janés.

Taibo II, Paco Ignacio y Subcomandante Marcos (2005): Muertos incómodos, México: Planeta.

VANDEN BERGHE, Kristine (2005): Narrativa de La rebelión zapatista. Los relatos del Subcomandante Marcos, Madrid/Frankfurt: Iberoamericana/Vervuert.

VÁzquez Montalbán, Manuel (1999): Marcos: El señor de los espejos, Madrid: Aguilar. 